\title{
First Report of Hartertia Gallinarum in Domestic Pigeons (Columba Livia) in Iran
}

\author{
Zainab Sadeghi Dehkordi* \\ Departmet of Parasitology, Bu- Ali Sina Uiversity, Iran
}

*Corresponding author: Zainab Sadeghi Dehkordi, Departmet of Parasitology, Faculty of Veteriary Science, Bu- Ali Sina Uiversity, Hamedan, Iran, Fax: 08114227475; Tel: 09132835171; Email: dehkordisz@gmail.com

Submission: :

\begin{abstract}
In September 2017, a 1 years old domestic pigeon (Columba domestica) was anatomized. Gastrointestinal tract of the bird was opened. During this study numerous nematodes were found. After fixation and morphological examination the two worms were identified as Hartertia gallinarum. The worms were observed and identified by light microscopy on the basis of features at the anterior and posterior parts of the worms. The worms were Hartertia gallinarum. In addition, our results showed that among 40 birds, 20 (50\%) were infected with Haemoproteus columbae. All other helminth infection have been reported as follows: Raillietina achinobothridia (10\%), Ascaridia colombae (12.5\%), Ascaridia galli (82.5\%). 3 different species of ectoparasites identified were Pseudolynchia canariensis (25\%), Columbicola columbae (62.5\%) and Menopon gallinae (15\%). The present study is the first report on Hartertia gallinarum in domestic pigeons (Columba livia) in Iran.
\end{abstract}

Keywords: Columba livia; Hartertia gallinarum; Hamedan

\section{Case Report}

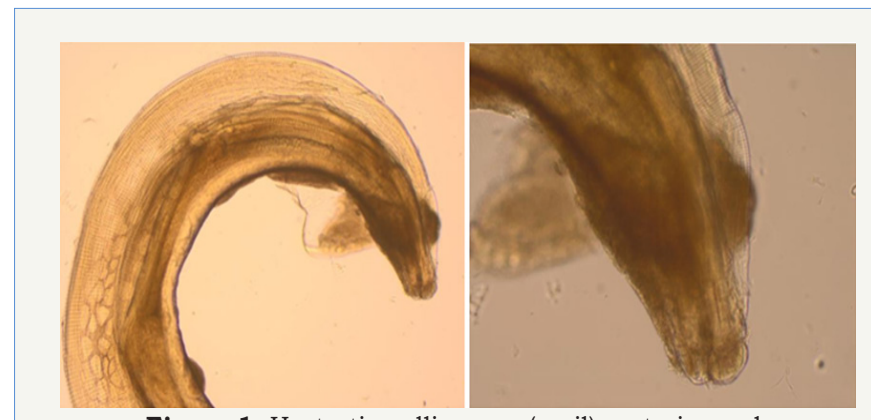

Figure 1: Hartertia gallinarum (mail): anterior end.

The nematode Hartertia gallinarum is well known as a spiruroid parasite of the small intestine of chickens in Africa and transmitted to the final host by the workers of ants and termites [1-3]. Hartertia gallinarum found in the intestine of fowls and wild bustards can cause emaciation, weakness and diarrhea, transmits Histomonas meleagridis. While checking the small intestine of indigenous pigeons of Hamedan, two nematodes (5\%) were found in a pigeon. The cases have symptoms such as loss of body weight, anorexia, diarrhea, and dehydration. Mix infections of two or more species of parasites were reported in this case. At necropsy, each section of gastrointestinal tract of the bird was opened, separately, and then removed contents were examined under a stereo microscope for parasite helminthes. The respiratory tract was opened and the internal surface of the trachea was inspected. All nematodes removed from mentioned organs were placed in AFA solution (alcohol, formaldehyde, acetic acid, distilled water, and glycerine), and then cleared with lactophenol (25\% glycerine, 25\% lactic acid, $25 \%$ phenol and $25 \%$ distilled water).

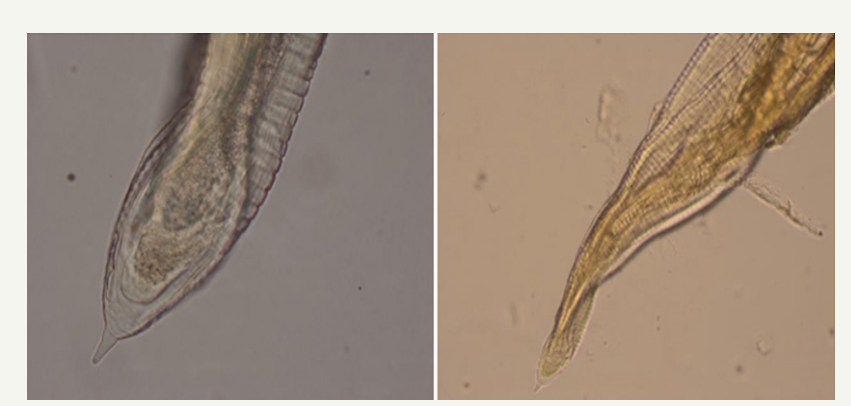

Figure 2: Hartertia gallinarum (mail): posterior end.

This species was obtained from small intestine of domestic pigeon with a prevalence of $5 \%$ Worms of fine and elongated body. Lateral flanges very narrow, limited to anterior part of body. Cervical papillae just behind lips, Mouth tow, large, trilobite, lateral lips. The cuticle of the inner surface of each lip is thickened, toothed, and thrown into folds interlocking with those of the opposite side. Each lip with a lateral papilla and a pair of submedian papillae, interlabia small or rudimentary. Vestibule short, esophagus divided into two parts, of which the anterior is short and muscular. The mean important measurements of 2 male parasites are as following: Hartertia gallinarurn (Theiler 1919) (Spiruoidea. Spiruridae). Male: total length $35 \mathrm{~mm}$, maximum width $0.49 \mathrm{~mm}$ 
left spicule $2 \mathrm{~mm}$ right spicule $0.48 \mathrm{~mm}$. The posterior extremity tubercular (Figure $1 \& 2$ ).

\section{Discussion}

Previously, other researcher has been reported Hartertia gallinarum on fowl in southern part of Iran. Specimens of the parasite of this study are slightly smaller than those reported by Eslami \& Mozafarinejad [4] and Kotlan [1], but they fit well in other characters, the present study is the first report on Hartertia gallinarum in domestic pigeons (Columba livia) in Iran. Because of macroscopic similarities between the morphology of this nematode and that of Ascaridia galli, another small intestine nematode, it is much probable that poultry practitioners take one of these two species for the other. To prevent this in the present short note, in addition the microscopic differences in the morphology of these two species, their life cycle, pathogenecity, and treatment were compared and discussed [4]. Mixed infections of two or more species of parasites per bird was common in the present study. This might be attributed to food preference at a particular time which determines the establishment of mixed or single infection. Our results are in accordance with Kennedy [5]. Also, t he present specimens of Hartertia gallinarum are slightly smaller than those reported by Mohammad 1996 who recorded it in the caecum of A. graecain Gara-area, Rutba, west of Iraq. Later, it was reported. Mahmoud et al. [6] found that comparable ecological conditions ans seasons could be factors influencing the prevalence of Hartertia gallinarum in birds in the western of Iraq. Other Study on the parasites of chukar partridge Alectoris chukar from Shaqlawa district, Kurdistan region, Iraq showed that the existence of five species of parasites including: one species of digenetictrematode (Dicrocoelium petrowi), two species of cestodes (Cotugnia latiproglottina and Raillietina alectori) and two species of nematodes (Ascaridia numidae and Hartertia gallinarum [7]. Although this is the first report on Hartertia gallinarum in domestic pigeons (Columba livia) in Iran, but this needs to be investigated more in other birds, as there is not any report of Hartertia gallinarum in Hamedan province so far [8].

\section{Acknowledgment}

The author would like to thank Younes Rostami, Danial Yousefnia and Ebrahim Kargar for help in sample collection. Also, the author is grateful to Dr. Heidari and Saskineh Azami for to their aid in the laboratory diagnosis.

\section{References}

1. Kotlan A (1960) Helminthogie. Akademiai kiado Budapest.

2. Chandler AC, Read CP (1961) Introduction to parasitology with special reference to the parasites of man. John Wiley and Sons Inc, New York, USA.

3. Yamaguti S (1961) Systema helminthum. The nematodes of vertebrates. Interscience publishers Inc, New York, USA.

4. Eslami A, Mozaffari H (1993) Occurance of in the indigenous chicken of Southern part of Iran. Vet Res 47: 121-124.

5. Kennedy CR (1975) Ecological animal parasitology. Blackwell Scientific Publications, Melbourne, Australia.

6. Mahmoud SS, Mohammad MK, Au SY (2000) Intensity and histopathological effects of the nematode Hartertia gallinarum on seesee partridge, ammoperdix griseogularis collected from QA, Raea, west of Iraq. Bull Iraq nat Hist Mus 9(2): 45-55.

7. Zhala OI, Khoshnaw MS, Abdullah A (2013) Study on the parasites of chukar partridge Alectoris chukar from Shaqlawa district, Kurdistan region, Iraq. Tikrit Journal of Pure Science 18(3): 1813-1662.

8. Luka SA, Ndams IS (2007) Gastrointestinal parasites of domestic chicken gallus domesticus Linnaeus 1758 in samara, Zaria Nigeria. Scienc World Journal 2: 1 .
Creative Commons Attribution 4.0 International License

For possible submissions Click Here
Submit Article

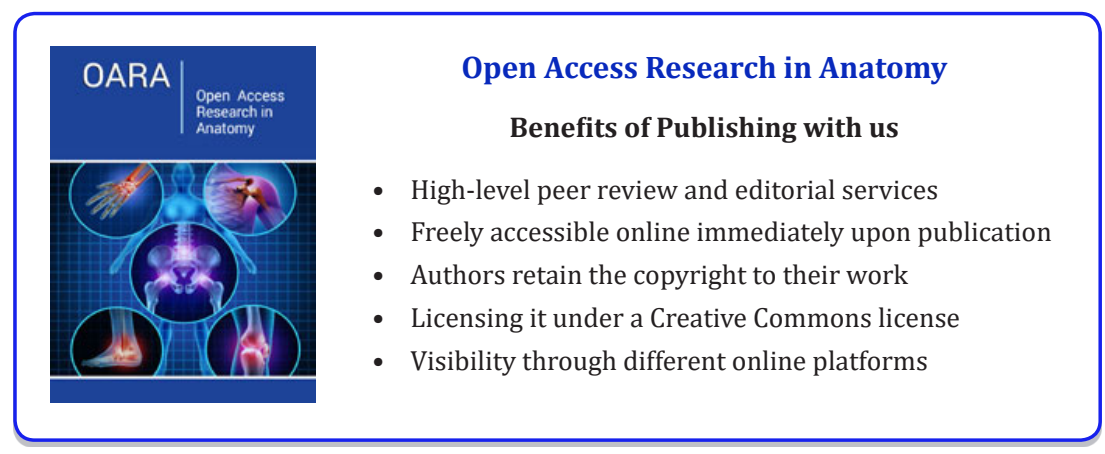

